women were found with abnormal pap smear findings, with some found with cervical cancer.

Discussion Malaysia as a nation is facing a new challenge in sustaining the productivity of employees. The findings of the health status of Malaysian employees, showed much higher prevalence of non-communicable disease risk factors compared to what it was 10 years ago. To curb the epidemic and its impact to both businesses and the nation, a concentrated effort involving the government, the employees and the employers are required.

\section{ASSOCIATION BETWEEN WORKPLACE BULLYING AND COMMON MENTAL DISORDERS IN BRAZILIAN CIVIL SERVANTS}

${ }^{1}$ Fernando Feijo, ${ }^{2}$ Eduarda Buriol, ${ }^{3}$ Cristiane Bunchen, ${ }^{2}$ Paulo Antonio Oliveira, ${ }^{3}$ Mayte Amazarray. ${ }^{1}$ Federal University Of Pelotas, Pelotas, Brazil, ${ }^{2}$ Federal University of Rio Grande do Sul, Porto Alegre, Brazil, ${ }^{3}$ Federal University of Health Sciences, Porto Alegre, Brazil

\subsection{6/oemed-2018-ICOHabstracts. 1592}

Introduction Bullying has been described in literature as an important determinant for workers mental health. We aimed to evaluate the association between workplace bullying and common mental disorders in a sample of Brazilian civil servants.

Methods Cross-sectional study with a sample of 1883 workers from the Brazilian Federal Judiciary. The Negative Acts Questionnaire (NAQ-r) was used to measure bullying at work and the Self Report Questionnaire (SRQ-20) was used to evaluate Common Mental Disorders (CMD). Poisson and logistic regressions were used to test associations of interest, controlling for confounders.

Results The overall prevalence of CMD was $27.1 \%$. The prevalence of workplace bullying was $17.0 \%$. In the regression analysis controlling for social, demographic and occupational confounders, workers exposed to occasional bullying (now and then or monthly negative acts) was associated with a 2.17-fold higher prevalence of CMD $(\mathrm{p}<0.001)$. Subjects exposed to bullying frequently (weekly or daily negative acts) presented a 4.78-fold higher prevalence of CMD than those who did not suffer bullying $(\mathrm{p}<0.001)$.

Discussion Very few studies on the association between bullying and mental health in low and middle income countries are published. Our findings corroborate the results of longitudinal studies from high-income countries, where bullying appears to be an important determinant of worse mental health. Prevention actions to eliminate bullying in organisations are urgent, in order to preserve workers mental health. Civil servants are at high risk of being exposed to bullying, worsening their health condition.

\section{SYSTEMATIC INTERVENTIONS TO REDUCE PSYCHOSOCIAL FACTORS IMPACT IN THE WORKPLACE}

Cecilia Colautti*, Javier Naveros, Sergio Orlandini Cappannari. Argentinean Association of Health Promotion, Buenos Aires, Argentina

\subsection{6/oemed-2018-ICOHabstracts. 1593}

Introduction The impact of psychosocial factors on work life and extra-work life is increasing. Globally, mental disorders, many of them chronic, will be the single most costly component in health. In 2010 the global cost of mental disorders was \$2.5 trillion, projecting an increase to \$6 trillion by 2030 . Depression costs more than cardiovascular disease, cancer and diabetes combined. The impact on work is undeniable and at the same time can be a scenario for improving the health and quality of life of employees. Psychosocial factors are decisive, both in relation to the causes and prevention of mental disorders and in health promotion. In the work context we call psychosocial risk factors to those factors that originate in the organisation of work and which generate physiological, emotional, cognitive and behavioural responses that require coping responses and that can be precursors of diseases in certain circumstances of Intensity, frequency, and duration when coping is inadequate or insufficient. In the last years the ways and techniques for measure psychosocial factors in the workplace were improving and providing a clearer scenario on this problem. The concept of stress was comprehensively understood, considering the negative and positive aspects. The abilities of people to be exposed to stressors are key in dimensioning psychosocial risk. Resilience emerges as a personal and relational skill that can be trained and strengthened.

Methods Depression, stress at home and work related stress, worksite psychosocial factors and resilience were measured in a people population compounded of employees of different companies located in Latin America. PHQ9, SSOS, ISTAS21 and Wagnild and Young resilience scale were used to measure previous and post intervention. We have developed strategies to manage psychosocial factors in the workplace based in applied neuroscience; work psycho sociology; cognitive behavioural therapy and health coaching are useful to reduce psychosocial factors and to develop personal and collective resources for mental wellbeing.

Result 50\% reduction in psychosocial risks impact in the workplace was achieved in a 400 employees population.

Discussion Systematic interventions are useful to reduce psychosocial factors and to develop personal and collective resources for mental wellbeing. Both, organisational and personal training are the key to promotion and protection of mental wellbeing in the workplace.

\section{STIGMA AND PUBLIC MENTAL HEALTH POLICY: PERSONAL, PROFESSIONAL, FAMILIAR AND SECURITY AND SOCIAL NATIONAL INSTITUTE LOSSES}

1,2,3,4,5 RN Rocha*, ${ }^{4,5,6}$ AG Silva, ${ }^{7}$ AP Diaz. 'International Commission on Occupational Health, Milano, Italy; ${ }^{2}$ Associação Nacional de Medicina do Trabalho, São Paulo, Brazil; ${ }^{3}$ Associação Brasiliense de Medicina do Trabalho, Brasilia, Brazil; ${ }^{4}$ Conselho Federal de Medicina, Brasilia, Brazil; ${ }^{5}$ Associação Psiquiátrica da América Latina, Antigua, Guatemala; ${ }^{6}$ Associação Brasileira de Psiquiatria, Rio de Janeiro, Brazil; ${ }^{2}$ Universidade do Sul de Santa Catarina, Santa Catarina, Brazil

\subsection{6/oemed-2018-ICOHabstracts.1594}

Introduction The process of stigmatisation of the mental illness is historical and goes back to the social conditions by which patients with mental disorders were submitted. Because of this, patients with psychiatric disorders are often assaulted, socially and even legally excluded because of the characteristics that arise from their illness. Besides, the mental health policy is based on ideological principles with no scientific guideline. This lecture intends to delineate a historical line on stigma, bringing to the present day the concept and path of meaning and current consequences in physical and legal life, propose a scientific guideline to the public mental health policy and describe the database on disease and concession of social security benefit due to mental disorder in Brazil. 